Hazardous Materials (HazMat) Medical Life Support Program in Singapore

M.K.F. Leong; R. Ponampalam; F.C.Y. Lee; S.H. Gob

Singapore General Hospital, Singapore

Funded by the Society for Emergency Medicine in Singapore and Ministry of Health

Singapore is the leading petrochemical production, storage, and trading hub in Southeast Asia. A potential exists for a technological disaster involving a wide variety of industrial chemicals. The 1995 Tokyo Subway Sarin Gas attack by the Aum Shinrikyo cult and the recent reports of terrorist activity in Singapore serve as a reminder that hazardous chemicals in the surrounding environment can have devastating effects on civilian populations, if chosen as a weapon by terrorists.

The Hazardous Materials (HazMat) Medical Life Support Program, founded in 1999, is a program funded by the Ministry of Health, which aims to provide education and training for medical, nursing, and paramedic staff, who may be called to respond and deal with a HazMat incident and its casualties. The program administers four courses, including those for the: (1) Basic Provider; (2) Hospital Provider; (3) Hospital Decontamination; and (4) HazMat Medical Operations. As HazMat incidents resulting in mass casualties are relatively infrequent events, the course format and materials are designed to provide a rational, practical, and easy to recall algorithm for the novice responder. Concepts, rather than a systemic coverage of all available chemicals, provide a mental and practical framework for the emergency medical worker to respond to an incident, as well as provide life support to HazMat casualties.

An example of a fundamental concept is the chain of survival of a HazMat casualty-early recognition and activation of the HazMat plan, administration of antidotes, decontamination, and HazMat medical life support. Issues pertaining to the triage, evaluation, and treatment of casualties in a potentially hazardous environment are covered with the teaching of a modified primary survey. The program also emphasizes the standardization of instruction, assessment of competency, and certification, and is an important tool for the employers to decide on the appropriate use of their staff in a HazMat incident.

Keywords: chemical; disaster; education; hazardous materials (HazMat); training

Prehosp Disast Med 2005;20(2):s17

Field Placement in Disasters: An Evaluation of the Experience of Students Obtaining Masters Degrees K. Davies

University of Glamorgan, United Kingdom

The Universities of Glamorgan and Ulster, in partnership with Hame Polytechnic (Finland), facilitate an MSc in Disaster Relief Healthcare. Students enrolled in the program must be placed in a disaster area or a developing country as an integral component of their studies. The stated aim of the experience is “... to provide students with direct experience of working and living in a disaster zone in order to facilitate synthesis of knowledge and skills gained in earlier modules of study." This presentation will report the findings of an audit of the placement of students in a disaster area in this MSc in Disaster Relief Healthcare program. Students reported great satisfaction with their learning experiences, but also, frustration. They emphasized the need for adequate preparation prior to placement, and were very positive about the simulations provided over three summer school sessions before deployment. Students reported that skills learned while on assignment have been transferable to their homeland employment, including assertiveness and an awareness of the importance of effective communication. This presentation will highlight the clear emphasis on cultural and role diversity, and the different modalities of healthcare provision within the placement zone. Additionally, students' reports on the expectations of populations in terms of their healthcare prospects will be elucidated. These are critical areas of study when one considers that many students find themselves placed in some of the most remote, challenging, and harsh environments on earth, often coupled with a degree of personal risk due to a worsening security situation.

Keywords: assessment; disaster relief health care; education; expectations; students; training placement

Prebosp Disast Med 2005;20(2):s17

\section{Role of Education in Disaster Management of the Bam Earthquake, Iran}

A. Pazouki, ${ }^{1}$ M. Pazouki, V. Entezari ${ }^{1}$

1. Iran University of Medical Sciences, Iran

2. Iran Social Security Organization, Iran

Introduction: Iran is vulnerable to natural disasters, with earthquakes causing the worst destruction and highest number of fatalities. Approximately every ten years, a major earthquake hits Iran, killing thousands of people and causing widespread destruction. A recent earthquake occurred in Bam, in southeastern Iran, on 26 December 2003.

The First Congress on Health, Medication, and Crisis Management in Disaster Incidents was held in Tehran in May 2003, about seven months before the Bam earthquake. The main goal of the Congress was to familiarize the medical society with the different aspects of medical disaster management and review previous experiences in the field. The Congress was held over three days, and included multiple presentations, plenary sections, and workshops. Almost all national governmental and non-governmental organizations related to the disaster sector participated in the Congress, and approximately 1,500 active medical practitioners attended the scientific programs.

Methods: This is a qualitative, case-report study about healthcare management during the Bam earthquake and the role of educational interventions such as the Congress in the performance of the Iran University of Medical Sciences (IUMS) disaster response team.

Results: The IUMS disaster response team was one of the first groups that arrived at the Bam airport in the early hours after the earthquake. The team consisted of five specialists (a general surgeon, orthopedic surgeon, neurosurgeon, anesthesiologist, and emergency medicine specialist), three residents, and one general practitioner, all of whom 